\title{
Impact of local steroid application on dysphagia following an anterior cervical discectomy and fusion: results of a prospective, randomized single-blind trial
}

\author{
Brittany E. Haws, BS, Benjamin Khechen, BA, Ankur S. Narain, BA, Fady Y. Hijji, MD, \\ Daniel D. Bohl, MD, MPH, Dustin H. Massel, MD, Benjamin C. Mayo, MD, Junyoung Ahn, MD, and \\ Kern Singh, MD
}

Department of Orthopaedic Surgery, Rush University Medical Center, Chicago, Illinois

OBJECTIVE Intraoperative local steroid application has been theorized to reduce swelling and improve swallowing in the immediate period following anterior cervical discectomy and fusion (ACDF). Therefore, the purpose of this study was to quantify the impact of intraoperative local steroid application on patient-reported swallow function and swelling after ACDF.

METHODS A prospective, randomized single-blind controlled trial was conducted. A priori power analysis determined that 104 subjects were needed to detect an 8-point difference in the Quality of Life in Swallowing Disorders (SWAL-QOL) questionnaire score. One hundred four patients undergoing 1- to 3-level ACDF procedures for degenerative spinal pathology were randomized to Depo-Medrol (DEPO) or no Depo-Medrol (NODEPO) cohorts. Prior to surgical closure, patients received $1 \mathrm{ml}$ of either Depo-Medrol (DEPO) or saline (NODEPO) applied to a Gelfoam carrier at the surgical site. Patients were blinded to the application of steroid or saline following surgery. The SWAL-QOL questionnaire was administered both pre- and postoperatively. A ratio of the prevertebral swelling distance to the anteroposterior diameter of each vertebral body level was calculated at the involved levels \pm 1 level by using pre- and postoperative lateral radiographs. The ratios of all levels were averaged and multiplied by 100 to obtain a swelling index. An air index was calculated in the same manner but using the tracheal air window diameter in place of the prevertebral swelling distance. Statistical analysis was performed using the Student t-test and chi-square analysis. Statistical significance was set at $p<0.05$.

RESULTS Of the 104 patients, 55 (52.9\%) were randomized to the DEPO cohort and 49 (47.1\%) to the NODEPO group. No differences in baseline patient demographics or preoperative characteristics were demonstrated between the two cohorts. Similarly, estimated blood loss and length of hospitalization did not differ between the cohorts. Neither was there a difference in the mean change in the scaled total SWAL-QOL score, swelling index, and air index between the groups at any time point. Furthermore, no complications were observed in either group (retropharyngeal abscess or esophageal perforation).

CONCLUSIONS The results of this prospective, randomized single-blind study did not demonstrate an impact of local intraoperative steroid application on patient-reported swallowing function or swelling following ACDF. Neither did the administration of Depo-Medrol lead to an earlier hospital discharge than that in the NODEPO cohort. These results suggest that intraoperative local steroid administration may not provide an additional benefit to patients undergoing ACDF procedures.

- CLASSIFICATION OF EVIDENCE Type of question: therapeutic; study design: randomized controlled trial; evidence: Class I.

Clinical trial registration no.: NCT03311425 (clinicaltrials.gov)

https://thejns.org/doi/abs/10.3171/2017.11.SPINE17819

KEYWORDS anterior cervical discectomy and fusion; Depo-Medrol; swallowing; prevertebral swelling; intraoperative steroid

ABBREVIATIONS ACDF = anterior cervical discectomy and fusion; $\mathrm{AP}=$ anteroposterior; $\mathrm{BMI}=$ body mass index; $\mathrm{CCl}=\mathrm{Charlson} \mathrm{Comorbidity} \mathrm{Index;} \mathrm{EBL}=$ estimated blood loss; LOS = length of hospital stay; PSTS = prevertebral soft-tissue swelling; SWAL-QOL = Quality of Life in Swallowing Disorders; VAS = visual analog scale. SUBMITTED July 24, 2017. ACCEPTED November 20, 2017.

INCLUDE WHEN CITING Published online April 20, 2018; DOI: 10.3171/2017.11.SPINE17819. 


\section{- CLASSIFICATION OF EVIDENCE}

Type of Question Therapeutic

Study Design Randomized controlled trial

Evidence Class I

\section{Summary Statement}

In patients undergoing anterior cervical discectomy and fusion (ACDF), this class I study found no improvement in postoperative dysphagia, as measured by the SWAL-QOL survey, from intraoperative local steroid application plus 10 $\mathrm{mg}$ of intravenous dexamethasone compared to intravenous dexamethasone alone.

\section{Classification of Evidence}

Class I randomized controlled trials (RCTs) are rare and precious in the medical literature, and studies that do not resort to esoteric statistical manipulations to fortify their conclusions are an equally uncommon treasure. Haws and colleagues provide both commodities in their paper. This trial fulfills all of the requirements of a class I study: similar baseline characteristics between treatment groups, adequate randomization, allocation concealment, masked outcome assessment, a prespecified primary end point, acceptable loss to followup (14\% in each treatment arm), and an intention-to-treat analysis. The authors do append $p$ values to their table of baseline characteristics (Table 1), and they also characterize two intraoperative measures (operative time and estimated blood loss, Table 2) as "outcomes" when they might more accurately be included as potential between-group confounding features. As we have discussed in these statistical summaries before, $p$ values serve a straightforward role in research papers: to alert readers to the potential role of chance as a cause of between-group differences. In RCTs, differences between treatment groups must be due to chance (unless the randomization process was corrupt), so the addition of $p$ values is superfluous. The relevant question is whether the between-group differences are clinically important. One could argue that a $10.6 \%$ excess of obese (BMI > 30) patients in the topical steroid treatment arm could have made it more difficult to demonstrate a benefit of therapy if one existed. In contrast, a 6.5-minute difference in operative time (shorter in the steroid arm) could have reduced the frequency of postoperative dysphagia. Differences in characteristics of potential prognostic importance ("confounders" in statistical jargon) are always concerning, whether trials are randomized or observational, and statisticians have a technique for adjusting for known confounders: multivariate or multivariable analysis. The authors might have applied this strategy to prove to their readers that these ostensibly minor differences were not, in fact, the true drivers of their result, but this seems unlikely from a clinical perspective. Two other features of this study deserve brief comment. The authors, to their additional credit, identified an a priori clinically meaningful difference in outcomes (an 8-point difference in SWAL-QOL scores) for their trial and used this value to estimate a required sample size. The validity of this end point can be debated, but the authors are transparent in their assumptions. One might also wonder whether the authors should have asked a different research question: the benefit of topical steroid application versus intravenous dexamethasone. Instead, since both treatment arms received intraoperative dexamethasone, the authors can only assert that topical steroid application does not provide additional benefit with respect to postoperative dysphagia beyond that afforded by intravenous dexamethasone.

$$
\begin{array}{r}
\text { — Michael Glantz, MD } \\
\text { Hershey Medical Center } \\
\text { Hershey, Pennsylvania }
\end{array}
$$

$\mathrm{D}$ YSPHAGIA is one of the most frequently reported complications following anterior cervical discectomy and fusion (ACDF), with a reported incidence as high as $79 \%{ }^{1,4,6,15}$ While most cases are transient and resolve within 3 months, persistent dysphagia lasting 5 years has been reported in as much as $15 \%$ of patients. ${ }^{1,8,9,13,19,21}$ Although the exact pathophysiological mechanism has not been fully outlined, it is theorized that increased prevertebral soft-tissue swelling (PSTS) is a strong contributor in the postoperative setting. ${ }^{1,10,16}$

While some surgeons believe that dysphagia is an inevitable outcome of anterior cervical spine surgery, ${ }^{3,4}$ others have investigated potential methods of reducing its incidence and severity. Initially, the effect of perioperative systemic steroids was examined., ${ }^{2,14,20}$ More recently, the administration of local steroids directly at the surgical site prior to skin closure has drawn significant interest.,11

The reported effects of local or systemic intra- or postoperative steroids on postoperative swelling and dysphagia have been conflicting. ${ }^{7,11,14,20}$ However, the association between local application of steroids and postoperative swelling and dysphagia has not been well characterized. Therefore, the purpose of this study was to quantify the effect of intraoperative local steroid administration on postoperative swelling and dysphagia through a prospective, randomized single-blind study.

\section{Methods}

\section{Patient Population}

This study was approved by our institutional review board and is registered with the clinicaltrials.gov database (http://clinicaltrials.gov), and its registration number is NCT03311425. Patients scheduled to undergo a primary 1- to 3-level ACDF were considered for inclusion in the study. Patients were excluded if they had any allergy or contraindication to medications used in the protocol, had a medical history significant for a gastrointestinal bleed or dysphagia, or had experienced cervical spine trauma. Once the patients consented to the study, they were randomized into Depo-Medrol (DEPO) or no Depo-Medrol (NODE$\mathrm{PO}$ ) cohorts via a computerized random number generator. Randomization was performed 1 day prior to surgery by an investigator who did not participate in the patients' clinical care. A total of 121 patients were enrolled between August 2014 and March 2017 (DEPO = 64 patients, NODEPO = 57 patients). Patients were blinded to their cohort randomization, but the senior surgeon was not. Furthermore, data collection was performed by investigators blinded to the 
assigned treatment arms to prevent any biases during survey administration or radiographic measurement. We hypothesized that patients undergoing ACDF who receive local Depo-Medrol along with the systemic dexamethasone would have no difference in the incidence and duration of postoperative 1) swallowing function as determined by the Quality of Life in Swallowing Disorders (SWAL-QOL) questionnaire, 2) PSTS, 3) length of hospital stay (LOS), and 4) short- and long-term clinical outcomes compared with patients receiving only systemic dexamethasone.

\section{Power Analysis}

A priori power analysis was conducted based on a previous cohort that had undergone ACDF performed by the same surgeon. The average SWAL-QOL score in that cohort was $88.6 \pm 14.3$ at the 6 -week postoperative visit. Using this previously obtained information, we set an 8-point difference in SWAL-QOL score between the groups as the minimum needed for clinical relevance. Using a mean and standard deviation of $88.6 \pm 14.3$ for the control group, we determined that 104 patients would be needed to detect an 8-point difference in SWAL-QOL scores at 6 weeks postoperatively, with a power of $80 \%$ and an alpha of 0.05 .

\section{Surgical Technique}

Following proper patient positioning, intubation, and draping, fluoroscopic images were obtained for pathology localization. Once the pathology was oriented, a $2-\mathrm{cm}$ skin incision was made lateral to the midline, and a standard right-sided Smith-Robinson approach was used. ${ }^{18}$ Local bone graft obtained from the endplate preparation and nanOss bone graft substitute were used to fill an appropriately sized interbody cage that was subsequently impacted into place and secured using anterior spinal instrumentation. After final cage placement, patients randomized to the DEPO cohort received $1 \mathrm{ml}$ of 40-mg Depo-Medrol applied retroesophageally, directly to the surgical site, via a $100-\mathrm{mm}^{2}$ Gelfoam carrier. Patients randomized to the NODEPO cohort received $1 \mathrm{ml}$ of saline applied retroesophageally, directly to the surgical site, using the same Gelfoam carrier. Both cohorts received $10 \mathrm{mg}$ of intravenous dexamethasone intraoperatively.

\section{Demographic and Clinical Outcome Analysis}

Patients were analyzed in terms of the following demographic, comorbidity, and perioperative variables: age, sex, body mass index (BMI), smoking status, number of operative levels, and Charlson Comorbidity Index (CCI). Perioperative variables included operative time, estimated blood loss (EBL), and LOS. Complication rates were also investigated in the perioperative and postoperative period. Visual analog scale (VAS) neck and arm pain scores were assessed at preoperative and 6- and 12-week postoperative time points. Swallowing function was assessed using the SWAL-QOL preoperatively and at the 6- and 12week postoperative visits. Surveys were completed either on paper or electronically via tablet or computer before meeting with the surgeon for each patient's preoperative and postoperative clinical visits. The SWAL-QOL survey is composed of 13 multipart questions. Our analysis

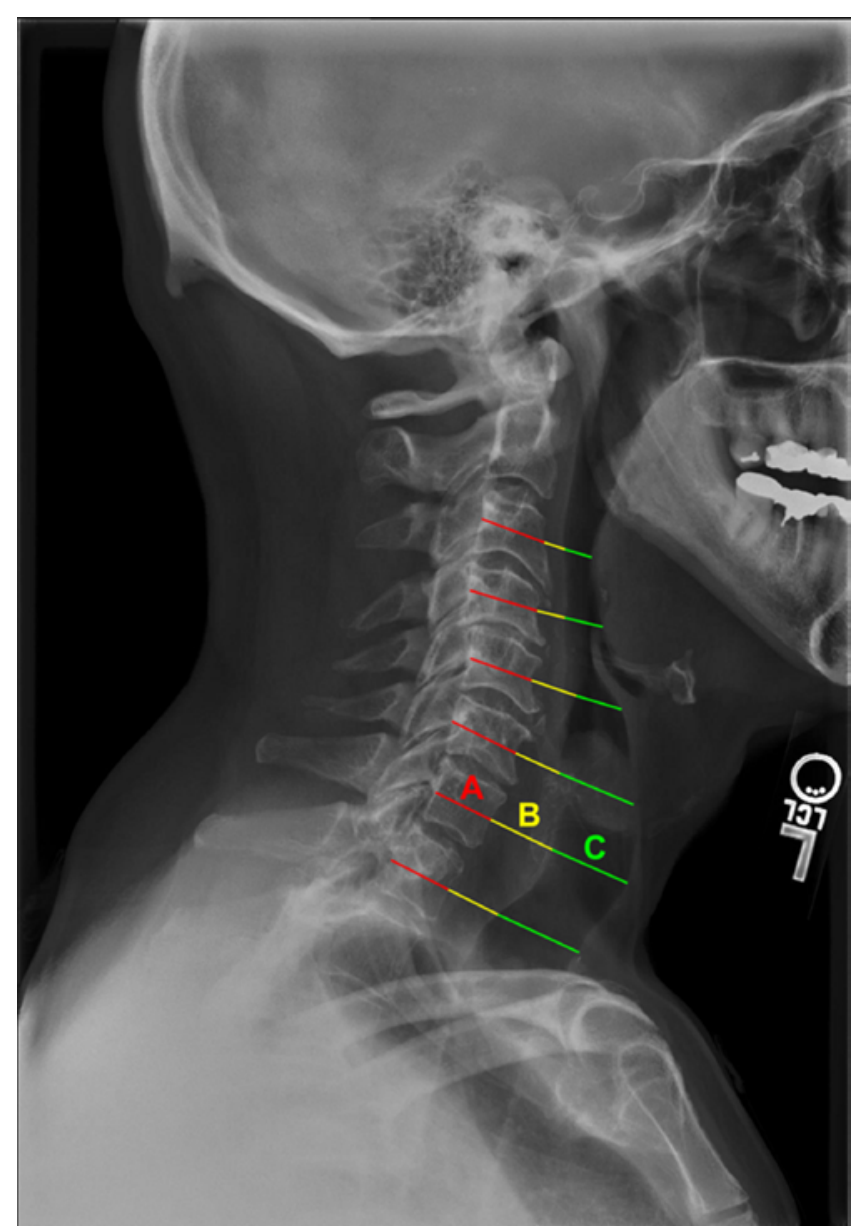

FIG. 1. Preoperative sagittal radiograph demonstrating the measurements analyzed. The vertebral body AP diameter (A), as well as all subsequent measurements, was taken mid vertebral body, parallel to the intervertebral disc for the index-level vertebral bodies, as well as 1 vertebral level above and below the level of fusion. The PSTS distance was measured from the anterior cortex of the vertebral body to the posterior tracheal air window (B). The tracheal air window diameter was measured within the same plane as the other 2 measurements $(C)$. Figure is available in color online only.

used only the third question, containing 14 total responses pertaining to the physical problems associated with swallowing difficulty (Supplemental Appendix A). Siska et al. previously described this approach to the SWAL-QOL questionnaire for postoperative dysphagia assessment. ${ }^{17}$ Each response indicated how often a patient experienced the designated problem on a scale of 1 ("almost always") to 5 ("never"). A maximum score of 70 , scaled to 100 , indicated that patients did not experience any swallowing difficulty. A minimum score of 20 indicated that patients suffered from each issue almost always.

\section{Radiographic Outcome Analysis}

Preoperative and 6-week and 12-week postoperative plain radiographs were obtained and analyzed (Fig. 1). The vertebral body anteroposterior (AP) diameter, as well as all subsequent measurements, was taken mid vertebral body, parallel to the intervertebral disc for the index-level 


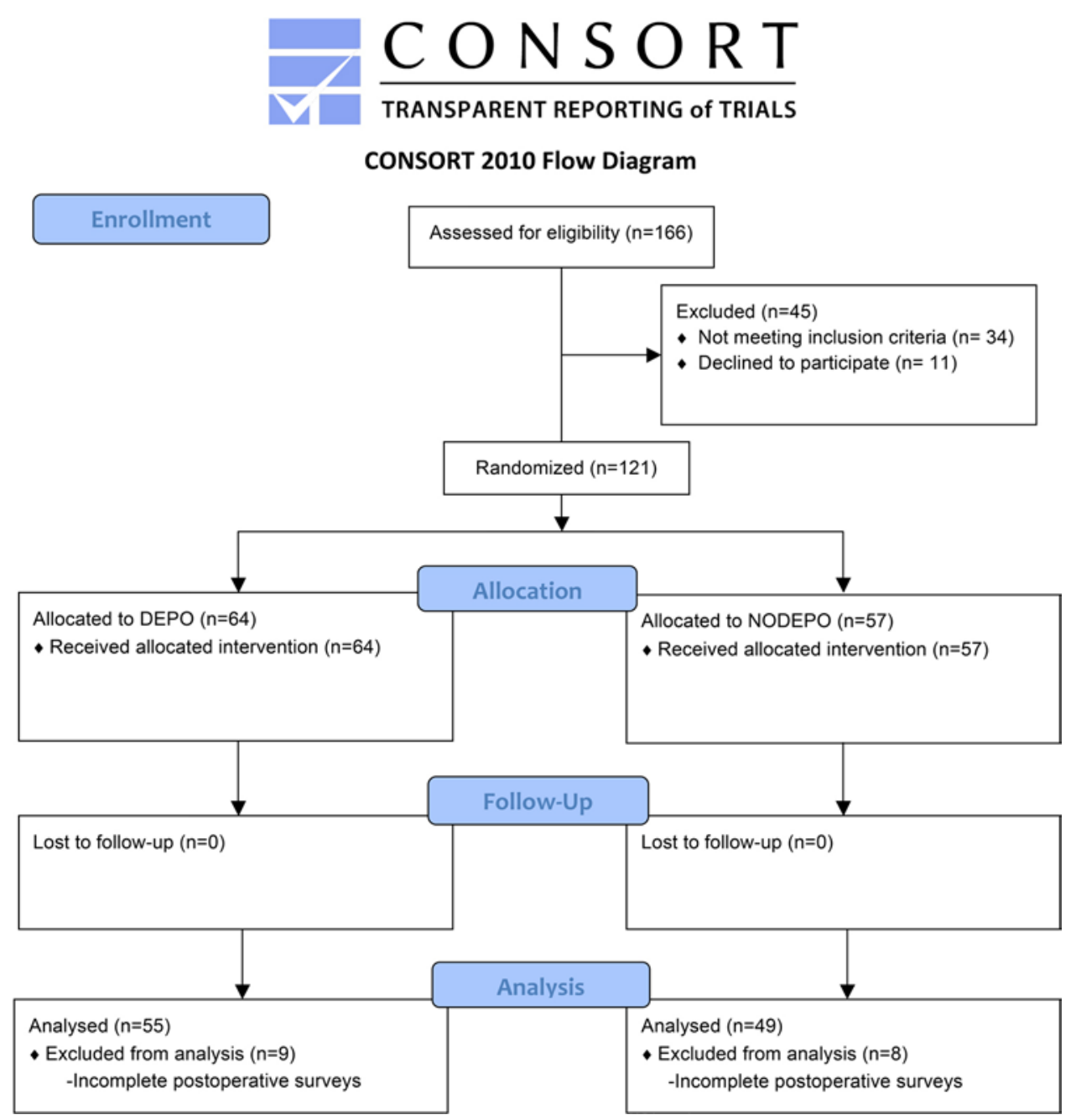

FIG. 2. CONSORT diagram detailing the flow of participants in the study. Template of the CONSORT flow diagram downloaded from http://www.consort-statement.org/consort-statement/flow-diagram. Figure is available in color online only.

vertebral bodies, as well as 1 vertebral level above and below the level of fusion. For example, a C4-5 ACDF would include measurements taken for the index level (C-4 and C-5) and 1 vertebral level above (C-3) and 1 below (C6 ). The PSTS distance was measured from the anterior cortex of the vertebral body to the posterior tracheal air window. The tracheal air window diameter was also measured within the same plane as the previous 2 measurements. The ratios of the prevertebral swelling distance to the vertebral body AP diameter at all levels were averaged and multiplied by 100 to obtain a swelling index. ${ }^{11}$ The air index was calculated in a similar manner utilizing the tracheal air window diameter instead of the prevertebral swelling distance.

\section{Statistical Analysis}

Statistical analysis was performed using Stata/SE 13.0 for Windows (StataCorp LP). Patient demographic, comorbidity, and procedural characteristic differences were tested using chi-square analysis and independent sample ttests for categorical and continuous variables, respectively.
Independent sample t-tests were used to assess differences between DEPO and NODEPO cohorts with respect to perioperative variables and postoperative outcomes. A p value $<0.05$ was used to determine statistical significance.

\section{Results}

A total of 121 patients were enrolled and randomized and received the intended intervention between $\mathrm{Au}-$ gust 2014 and March 2017 (Fig. 2). Of these, 17 (14.0\%) had incomplete postoperative SWAL-QOL survey data and were excluded from the analysis (DEPO: 9 patients [14.1\%]; NODEPO: 8 patients [14.0\%]). Therefore, 104 patients were included in the analysis, of whom 55 (52.9\%) and $49(47.1 \%)$ were in the DEPO and NODEPO groups, respectively. Patient age, sex, BMI, smoking status, number of operative levels, CCI, and preoperative VAS scores were not different between the cohorts $(p>0.05$; Table 1$)$.

Table 2 contains perioperative outcome comparisons. Perioperative variables such as EBL and LOS were no different between the DEPO and NODEPO cohorts. A 
TABLE 1. Baseline characteristics

\begin{tabular}{lccc}
\hline \multicolumn{1}{c}{ Parameter } & $\begin{array}{c}\text { NODEPO } \\
\text { Group }\end{array}$ & $\begin{array}{c}\text { DEPO } \\
\text { Group }\end{array}$ & $\begin{array}{c}\text { p } \\
\text { Value }^{*}\end{array}$ \\
\hline No. of patients & 49 & 55 & \\
\hline Mean age in yrs & $50.6 \pm 9.9$ & $49.4 \pm 10.3$ & 0.555 \\
\hline Sex & & & 0.615 \\
\hline Female & $38.8 \%(19)$ & $43.6 \%(24)$ & \\
\hline Male & $61.2 \%(30)$ & $56.4 \%(31)$ & \\
\hline BMl & & & 0.278 \\
\hline Nonobese $\left(\mathrm{BMl}<30 \mathrm{~kg} / \mathrm{m}^{2}\right)$ & $63.3 \%(31)$ & $52.7 \%(29)$ & \\
\hline Obese (BMI $\left.\geq 30 \mathrm{~kg} / \mathrm{m}^{2}\right)$ & $36.7 \%(18)$ & $47.3 \%(26)$ & \\
\hline Smoking status & & & 0.867 \\
\hline Nonsmoker & $91.8 \%(45)$ & $90.9 \%(50)$ & \\
\hline Smoker & $8.2 \%(4)$ & $9.1 \%(5)$ & \\
\hline No. of op levels & & & 0.569 \\
\hline 1 & $55.1 \%(27)$ & $52.7 \%(29)$ & \\
\hline 2 & $34.7 \%(17)$ & $41.8 \%(23)$ & \\
\hline 3 & $10.2 \%(5)$ & $5.5 \%(3)$ & \\
\hline CCl & $1.3 \pm 1.3$ & $1.6 \pm 1.9$ & 0.305 \\
\hline Mean preop VAS neck score & $5.7 \pm 2.5$ & $6.0 \pm 2.9$ & 0.633 \\
\hline
\end{tabular}

Values expressed as the mean \pm standard deviation or as percentage (number), unless indicated otherwise.

* The $p$ values were calculated using the Student t-test and chi-square analysis for continuous and categorical variables, respectively.

statistically significant decrease in operative time was observed in the DEPO group (48.4 vs 54.9 min, respectively, $\mathrm{p}=0.040$ ) compared with the NODEPO group; however, this difference was not clinically significant. The SWALQOL survey results demonstrated no difference in patientreported swallowing function between the cohorts at all time points assessed (preoperatively, 6 and 12 weeks postoperatively). Additionally, there were no differences in the change in SWAL-QOL scores from preoperative to the 6or 12-week postoperative visits between the cohorts. No complications were observed in either cohort. Specifically, no patients in either group developed a retropharyngeal abscess or esophageal perforation.

Radiographic outcome analysis is detailed in Table 3. Swelling indices were significantly different between the DEPO and NODEPO cohorts at the 6-week and 12-week postoperative visits (6 weeks: 77.7 vs 86.1 , respectively, $p$ $=0.017 ; 12$ weeks: 72.9 vs 80.2 , respectively, $p=0.032$ ), though not at the preoperative visit $(\mathrm{p}=0.137)$. In contrast, there were no differences in the change in the swelling index from preoperative to the 6- or 12-week postoperative values between the two cohorts ( $p>0.05$ each). No differences in the mean air index or the postoperative change in the air index existed at any time point between the DEPO and NODEPO cohorts ( $p>0.05$ for each).

Postoperative outcomes were further stratified by number of operative levels (Tables 4 and 5). Among the patients undergoing single-level ACDF, there were no differences in SWAL-QOL scores, swelling indices, or air indices between the DEPO and NODEPO cohorts ( $\mathrm{p}>$ 0.05 for each). Similarly, patients undergoing multilevel
TABLE 2. Perioperative swallowing outcomes

\begin{tabular}{lccc}
\hline \multicolumn{1}{c}{ Parameter } & $\begin{array}{c}\text { NODEPO } \\
\text { Group }\end{array}$ & $\begin{array}{c}\text { DEPO } \\
\text { Group }\end{array}$ & $\begin{array}{c}\text { p } \\
\text { Value* }\end{array}$ \\
\hline No. of patients & 49 & 55 & \\
\hline Mean op time in mins & $54.9 \pm 17.2$ & $48.4 \pm 13.7$ & 0.040 \\
\hline EBL in ml & $30.9 \pm 15.1$ & $31.7 \pm 12.9$ & 0.779 \\
\hline LOS in hrs & $16.8 \pm 11.9$ & $16.2 \pm 10.1$ & 0.760 \\
\hline Mean SWAL-QOL score $\dagger$ & & & \\
\hline Preop & $93.4 \pm 8.2$ & $92.5 \pm 9.6$ & 0.593 \\
\hline 6 wks postop & $90.9 \pm 11.5$ & $90.2 \pm 12.1$ & 0.789 \\
\hline 12 wks postop & $93.8 \pm 9.4$ & $90.6 \pm 12.2$ & 0.139 \\
\hline Mean change in SWAL- & & & \\
QOL score & & & \\
\hline Preop to 6 wks & $-2.1 \pm 8.6$ & $-2.1 \pm 10.3$ & 0.971 \\
\hline Preop to 12 wks & $0.4 \pm 7.6$ & $-1.9 \pm 9.8$ & 0.192 \\
\hline
\end{tabular}

Values expressed as the mean \pm standard deviation, unless indicated otherwise. Boldface type indicates statistical significance.

* The $p$ values were calculated using the Student t-test.

$\dagger$ SWAL-QOL scale $=0-100$, where $0=$ worse swallowing and $100=$ better swallowing.

ACDF did not demonstrate any differences in SWALQOL scores, swelling indices, or air indices between the DEPO and NODEPO cohorts ( $p>0.05$ for each).

Table 6 details postoperative changes in VAS neck and arm pain between the cohorts. Similar improvements in

\section{TABLE 3. Radiographic outcomes}

\begin{tabular}{|c|c|c|c|}
\hline Parameter & $\begin{array}{l}\text { NODEPO } \\
\text { Group }\end{array}$ & $\begin{array}{l}\text { DEPO } \\
\text { Group }\end{array}$ & $\begin{array}{c}p \\
\text { Value* }\end{array}$ \\
\hline No. of patients & 49 & 55 & \\
\hline \multicolumn{4}{|l|}{ Mean swelling index $\dagger$} \\
\hline Preop & $71.2 \pm 16.2$ & $65.8 \pm 17.8$ & 0.137 \\
\hline 6 wks postop & $86.1 \pm 15.7$ & $77.7 \pm 17.9$ & 0.017 \\
\hline 12 wks postop & $80.2 \pm 13.6$ & $72.9 \pm 18.2$ & 0.032 \\
\hline \multicolumn{4}{|l|}{ Mean swelling index changef } \\
\hline Preop to 6 wks postop & $15.8 \pm 15.4$ & $11.4 \pm 15.5$ & 0.183 \\
\hline Preop to 12 wks postop & $10.2 \pm 13.3$ & $7.3 \pm 15.4$ & 0.358 \\
\hline \multicolumn{4}{|l|}{ Mean air index $\uparrow$} \\
\hline Preop & $110.4 \pm 17.7$ & $115.0 \pm 22.4$ & 0.292 \\
\hline 6 wks postop & $107.6 \pm 18.6$ & $110.3 \pm 23.7$ & 0.536 \\
\hline 12 wks postop & $106.1 \pm 21.7$ & $111.1 \pm 29.8$ & 0.361 \\
\hline \multicolumn{4}{|l|}{ Mean air index change $\neq$} \\
\hline Preop to 6 wks postop & $-3.9 \pm 15.6$ & $-5.2 \pm 17.7$ & 0.721 \\
\hline Preop to 12 wks postop & $-5.2 \pm 15.9$ & $-0.9 \pm 25.0$ & 0.364 \\
\hline
\end{tabular}

Values expressed as the mean \pm standard deviation, unless indicated otherwise. Boldface type indicates statistical significance.

* The $p$ values were calculated using the Student t-test.

$\dagger$ Mean air/swelling index $=$ mean of tracheal air/pretracheal swelling measurement for index $\times 100$, index \pm 1 level.

$\ddagger$ Mean air/swelling index change = mean postoperative air/swelling index mean preoperative air/swelling index. 
TABLE 4. Single-level outcomes

\begin{tabular}{lccc}
\hline \multicolumn{1}{c}{ Parameter } & $\begin{array}{c}\text { NODEPO } \\
\text { Group }\end{array}$ & $\begin{array}{c}\text { DEPO } \\
\text { Group }\end{array}$ & $\begin{array}{c}\text { p } \\
\text { Value* }\end{array}$ \\
\hline No. of patients & 27 & 29 & \\
\hline Mean SWAL-QOL score & & & \\
\hline Preop & $94.3 \pm 8.3$ & $92.7 \pm 8.6$ & 0.476 \\
\hline Preop to 6 wks postop change & $-0.5 \pm 5.9$ & $-3.3 \pm 12.3$ & 0.329 \\
\hline Preop to 12 wks postop change & $-0.7 \pm 6.2$ & $-3.0 \pm 12.0$ & 0.158 \\
\hline Mean swelling index & & & \\
\hline Preop & $75.3 \pm 15.2$ & $67.7 \pm 20.0$ & 0.130 \\
\hline Preop to 6 wks postop change & $12.0 \pm 13.4$ & $11.7 \pm 15.5$ & 0.939 \\
\hline Preop to 12 wks postop change & $7.0 \pm 8.4$ & $4.6 \pm 15.4$ & 0.524 \\
\hline Mean air index & & & \\
\hline Preop & $111.4 \pm 15.5$ & $120.1 \pm 24.8$ & 0.153 \\
\hline Preop to 6 wks postop change & $-3.5 \pm 13.5$ & $-6.9 \pm 15.3$ & 0.425 \\
\hline Preop to 12 wks postop change & $-3.7 \pm 15.2$ & $-0.4 \pm 27.6$ & 0.627 \\
\hline
\end{tabular}

Values expressed as mean \pm standard deviation, unless indicated otherwise.

* The $p$ values were calculated using the Student t-test.

VAS neck pain were observed between the DEPO and NODEPO groups at the 6-week and 12-week postoperative time points ( $\mathrm{p}>0.05$ each). Additionally, no differences were observed in VAS arm pain between the DEPO and NODEPO cohorts at either postoperative time point ( $p>0.05$ each).

\section{Discussion}

This prospective, randomized single-blind study com-

TABLE 5. Multilevel outcomes

\begin{tabular}{|c|c|c|c|}
\hline Parameter & $\begin{array}{l}\text { NODEPO } \\
\text { Group }\end{array}$ & $\begin{array}{l}\text { DEPO } \\
\text { Group }\end{array}$ & $\begin{array}{c}p \\
\text { Value* }\end{array}$ \\
\hline No. of patients & 22 & 26 & \\
\hline \multicolumn{4}{|l|}{ Mean SWAL-QOL score } \\
\hline Preop & $92.3 \pm 8.1$ & $92.3 \pm 10.8$ & 0.976 \\
\hline Preop to 6 wks postop change & $-3.9 \pm 10.6$ & $-0.5 \pm 6.6$ & 0.212 \\
\hline $\begin{array}{l}\text { Preop to } 12 \text { wks postop } \\
\text { change }\end{array}$ & $0.0 \pm 9.2$ & $-0.7 \pm 6.5$ & 0.774 \\
\hline \multicolumn{4}{|l|}{ Mean swelling index } \\
\hline Preop & $65.1 \pm 16.1$ & $63.8 \pm 15.2$ & 0.802 \\
\hline Preop to 6 wks postop change & $21.6 \pm 16.9$ & $11.1 \pm 15.9$ & 0.055 \\
\hline $\begin{array}{l}\text { Preop to } 12 \text { wks postop } \\
\text { change }\end{array}$ & $14.6 \pm 17.4$ & $10.0 \pm 15.3$ & 0.391 \\
\hline \multicolumn{4}{|l|}{ Mean air index } \\
\hline Preop & $109.2 \pm 20.7$ & $109.2 \pm 18.1$ & 0.996 \\
\hline Preop to 6 wks postop change & $-4.5 \pm 18.5$ & $-3.2 \pm 20.4$ & 0.849 \\
\hline $\begin{array}{l}\text { Preop to } 12 \text { wks postop } \\
\text { change }\end{array}$ & $-7.2 \pm 17.2$ & $-1.4 \pm 22.6$ & 0.398 \\
\hline
\end{tabular}

Values expressed as the mean \pm standard deviation, unless indicated otherwise.

* The $p$ values were calculated using the Student t-test.
TABLE 6. Pain outcomes

\begin{tabular}{lccc}
\hline \multicolumn{1}{c}{ Parameter } & $\begin{array}{c}\text { NODEPO } \\
\text { Group }\end{array}$ & $\begin{array}{r}\text { DEPO } \\
\text { Group }\end{array}$ & $\begin{array}{c}\text { p } \\
\text { Value* }\end{array}$ \\
\hline No. of patients & 49 & 55 & \\
\hline Mean change in VAS neck pain & & & \\
\hline Preop & $5.7 \pm 2.5$ & $6.0 \pm 2.9$ & \\
\hline Preop to 6 wks postop change & $-2.3 \pm 2.5$ & $-2.8 \pm 3.4$ & 0.406 \\
\hline Preop to 12 wks postop change & $-3.0 \pm 2.7$ & $-3.3 \pm 3.3$ & 0.697 \\
\hline Mean change in VAS arm pain & & & \\
\hline Preop & $5.8 \pm 2.3$ & $5.8 \pm 3.0$ & \\
\hline Preop to 6 wks postop change & $-3.5 \pm 2.6$ & $-3.2 \pm 3.3$ & 0.652 \\
\hline Preop to 12 wks postop change & $-3.8 \pm 2.7$ & $-2.6 \pm 3.9$ & 0.098 \\
\hline
\end{tabular}

Values expressed as the mean \pm standard deviation.

* The $p$ values were calculated using the Student t-test.

pared the effect of local steroid application on prevertebral swelling and patient-reported swallowing function after ACDF. The results suggested that the use of local intraoperative steroids does not result in significant improvement in patient-reported swallowing function compared with a control cohort.

The utility of steroids for the prevention of postoperative dysphagia has been investigated. Jeyamohan et al. ${ }^{7}$ performed a prospective, randomized double-blind controlled trial to evaluate the effect of perioperative systemic steroid administration on postoperative dysphagia and airway edema in 112 patients (56 per cohort) undergoing multilevel ACDF. The experimental cohort received intraoperative $(0.2 \mathrm{mg} / \mathrm{kg})$ and postoperative $(0.06 \mathrm{mg} / \mathrm{kg})$ intravenous dexamethasone every 6 hours for the first 24 hours after surgery. The control cohort received the same dosages of intravenous saline, administered in a similar manner. While the authors reported significantly lower rates of dysphagia in the immediate postoperative period as well as at the 1-month postoperative follow-up in the steroid cohort, the 3-, 6-, 12-, and 24-month follow-up time points revealed no difference in swallowing function between the cohorts. The authors also observed reduced fusion rates in the steroid cohort at 6 months, converging to similar fusion rates in the two patient groups at 12 and 24 months postoperatively.

The current study results differ from those in a similar prospective, randomized controlled trial performed by Edwards et al. in 2016. ${ }^{5}$ That study randomized 50 patients undergoing ACDF with bone morphogenetic protein to receive local Depo-Medrol or saline intraoperatively and evaluated dysphagia rates using the modified dysphagia scoring system. The experimental group demonstrated significantly reduced dysphagia scores as compared with those in the control group on postoperative days 4, 7, 14 , and 28. However, the time points at which dysphagia was evaluated were different from those in the current study, limiting our ability to compare outcomes between the studies.

Additionally, results of the present study contradict those in a prospective, randomized study performed by Lee et al. in 2011. ${ }^{11}$ That study examined the effect of a 
local steroid (40 $\mathrm{mg}$ triamcinolone) in the retropharyngeal space on PSTS, compared with a control, following ACDF. The authors demonstrated an increase in PSTS in the immediate postoperative period for both cohorts. They also reported a significant radiographic reduction in PSTS indices at 2 days and 2 weeks postoperatively in the steroid cohort compared with that in the control group. Despite evidence suggesting an improvement in PSTS in the steroid cohort versus controls, the study was limited by their definition of a PSTS index. The authors used the average value of PSTS at the C-3, C-4, and C-5 vertebral levels given the visibility on lateral radiographs, regardless of the operative pathological level, limiting the utility of the index in their analysis.

In the current study, no complications were observed in either cohort. Specifically, no patients developed an esophageal perforation or retropharyngeal abscess. Previous reports have suggested an association between these complications and local steroid application. Lee et al. examined 2 cases of delayed esophageal perforation following ACDF, one of which developed a subsequent retropharyngeal abscess. ${ }^{12}$ These authors identified the use of retropharyngeal steroids as a common finding in the cases and suggested their use as a contributing factor. They believed that retropharyngeal steroids may have inhibited the normal tissue healing process after microscopic intraoperative injury, allowing for the development of a defect in the esophagus. They cautioned against the use of retropharyngeal steroids in ACDF, primarily in patients with a history of chronic steroid use. In the present study, however, we did not find an association between local intraoperative steroid use and esophageal perforation, thus failing to substantiate this claim.

The current study has several limitations. First, all ACDF procedures were performed by a single surgeon at a single academic institution, limiting generalizability. Second, standard of care at the senior surgeon's institution does not include 2-week postoperative follow-up visits. Therefore, SWAL-QOL responses and radiographs were not obtained at this time point. This may have limited our analysis as dysphagia and swelling can be more severe in the early postoperative period. Furthermore, we did not assess outcomes beyond the 12-week time point. However, as dysphagia most often resolves within the first 3 months, ${ }^{1}$ we believe the time points in the present study to be of greatest relevance. The effect of local intraoperative steroid application on long-term outcomes, including fusion rates, is an aim of future study. Fourth, the use of intraoperative systemic steroids may have contributed to the observed results. However, as this use was standardized in both groups, we were able to isolate the specific utility of local steroid application on postoperative dysphagia rates. Finally, using the SWAL-QOL survey as our assessment tool of patient-reported dysphagia has its limitations. While the survey has been heavily used in the oropharyngeal oncological and otolaryngology literature, evidence for its efficacy in spine surgery is limited. Similarly, there are no studies that report SWAL-QOL score ranges corresponding to normal swallowing function or dysphagia. In an attempt to analyze pertinent information, we used only the most relevant questions in the sur- vey corresponding to the physical effects of swallowing dysfunction. The remainder of the survey corresponded to the quality of life variances as a result of swallowing dysfunction and demonstrated limited utility among our patient population.

\section{Conclusions}

The results of this prospective, randomized single-blind study suggest that the local application of Depo-Medrol does not improve patient-reported swallowing function after ACDF. Similarly, the local administration of DepoMedrol does not reduce prevertebral swelling after an ACDF. No complications were observed in either group, suggesting that local Depo-Medrol can be applied safely in patients undergoing ACDF procedures. However, intraoperative local Depo-Medrol application may not provide an additional benefit to patients undergoing ACDF procedures.

\section{Acknowledgments}

Dr. Singh has received a Cervical Spine Research Society Resident Grant unrelated to the present study.

\section{References}

1. Anderson KK, Arnold PM: Oropharyngeal dysphagia after anterior cervical spine surgery: a review. Global Spine J 3:273-286, 2013

2. Buttermann GR: Prospective nonrandomized comparison of an allograft with bone morphogenic protein versus an iliaccrest autograft in anterior cervical discectomy and fusion. Spine J 8:426-435, 2008

3. Campbell PG, Yadla S, Malone J, Zussman B, Maltenfort MG, Sharan AD, et al: Early complications related to approach in cervical spine surgery: single-center prospective study. World Neurosurg 74:363-368, 2010

4. Danto J, DiCapua J, Nardi D, Pekmezaris R, Moise G, Lesser M, et al: Multiple cervical levels: increased risk of dysphagia and dysphonia during anterior cervical discectomy. J Neurosurg Anesthesiol 24:350-355, 2012

5. Edwards CC II, Dean C, Edwards CC, Phillips D, Blight A: Can dysphagia following anterior cervical fusions with rhBMP-2 be reduced with local depomedrol application?: a prospective, randomized, placebo-controlled, double-blind trial. Spine (Phila Pa 1976) 41:555-562, 2016

6. Edwards CC II, Karpitskaya Y, Cha C, Heller JG, Lauryssen C, Yoon ST, et al: Accurate identification of adverse outcomes after cervical spine surgery. J Bone Joint Surg Am 86-A:251-256, 2004

7. Jeyamohan SB, Kenning TJ, Petronis KA, Feustel PJ, Drazin D, DiRisio DJ: Effect of steroid use in anterior cervical discectomy and fusion: a randomized controlled trial. J Neurosurg Spine 23:137-143, 2015

8. Kasimatis GB, Panagiotopoulos E, Gliatis J, Tyllianakis M, Zouboulis P, Lambiris E: Complications of anterior surgery in cervical spine trauma: an overview. Clin Neurol Neurosurg 111:18-27, 2009

9. Lee MJ, Bazaz R, Furey CG, Yoo J: Influence of anterior cervical plate design on dysphagia: a 2-year prospective longitudinal follow-up study. J Spinal Disord Tech 18:406-409, 2005

10. Lee MJ, Bazaz R, Furey CG, Yoo J: Risk factors for dysphagia after anterior cervical spine surgery: a two-year prospective cohort study. Spine J 7:141-147, 2007

11. Lee SH, Kim KT, Suk KS, Park KJ, Oh KI: Effect of ret- 
ropharyngeal steroid on prevertebral soft tissue swelling following anterior cervical discectomy and fusion: a prospective, randomized study. Spine (Phila Pa 1976) 36:22862292, 2011

12. Lee SH, Mesfin A, Riew KD: Delayed esophageal perforation after anterior cervical fusion and retropharyngeal steroid use: a report of two cases. Spine J 15:e75-e80, 2015

13. Lee SK, Lee GY, Wong GT: Prolonged and severe dysphagia following anterior cervical surgery. J Clin Neurosci 11:424427, 2004

14. Nam TW, Lee DH, Shin JK, Goh TS, Lee JS: Effect of intravenous dexamethasone on prevertebral soft tissue swelling after anterior cervical discectomy and fusion. Acta Orthop Belg 79:211-215, 2013

15. Rihn JA, Kane J, Albert TJ, Vaccaro AR, Hilibrand AS: What is the incidence and severity of dysphagia after anterior cervical surgery? Clin Orthop Relat Res 469:658-665, 2011

16. Riley LH III, Skolasky RL, Albert TJ, Vaccaro AR, Heller JG: Dysphagia after anterior cervical decompression and fusion: prevalence and risk factors from a longitudinal cohort study. Spine (Phila Pa 1976) 30:2564-2569, 2005

17. Siska PA, Ponnappan RK, Hohl JB, Lee JY, Kang JD, Donaldson WF III: Dysphagia after anterior cervical spine surgery: a prospective study using the swallowing-quality of life questionnaire and analysis of patient comorbidities. Spine (Phila Pa 1976) 36:1387-1391, 2011

18. Smith GW, Robinson RA: The treatment of certain cervicalspine disorders by anterior removal of the intervertebral disc and interbody fusion. J Bone Joint Surg Am 40-A:607-624, 1958

19. Smith-Hammond CA, New KC, Pietrobon R, Curtis DJ, Scharver $\mathrm{CH}$, Turner DA: Prospective analysis of incidence and risk factors of dysphagia in spine surgery patients: comparison of anterior cervical, posterior cervical, and lumbar procedures. Spine (Phila Pa 1976) 29:1441-1446, 2004

20. Song KJ, Lee SK, Ko JH, Yoo MJ, Kim DY, Lee KB: The clinical efficacy of short-term steroid treatment in multilevel anterior cervical arthrodesis. Spine J 14:2954-2958, 2014

21. Yue WM, Brodner W, Highland TR: Persistent swallowing and voice problems after anterior cervical discectomy and fusion with allograft and plating: a 5- to 11-year follow-up study. Eur Spine J 14:677-682, 2005

\section{Disclosures}

Dr. Singh owns stock with Avaz Surgical, LLC, and Vital 5; has been a consultant for DePuy, Zimmer, and Stryker; and has received royalties from Zimmer, Stryker, Pioneer, Lippincott Williams \& Wilkins, Thieme, Japee Publishing, and Slack Publishing.

\section{Author Contributions}

Conception and design: Singh, Massel, Mayo. Acquisition of data: Singh, Haws, Narain, Hijji, Massel, Mayo. Analysis and interpretation of data: Singh, Haws, Khechen, Narain, Hijji, Massel, Mayo, Ahn. Drafting the article: Singh, Haws, Khechen, Narain, Hijji, Massel, Mayo, Ahn. Critically revising the article: all authors. Reviewed submitted version of manuscript: all authors. Approved the final version of the manuscript on behalf of all authors: Singh. Statistical analysis: Singh, Haws, Khechen, Narain, Hijji, Bohl. Administrative/technical/material support: Singh, Haws, Khechen, Narain, Hijji, Bohl, Ahn. Study supervision: Singh, Haws, Khechen, Narain, Hijji.

\section{Supplemental Information \\ Online-Only Content}

Supplemental material is available with the online version of the article.

Supplemental Appendix A. https://thejns.org/doi/suppl/ 10.3171/2017.11.SPINE17819.

\section{Previous Presentations}

Portions of this work (preliminary data) were presented as proceedings at International Society for the Advancement of Spine Surgery 2017, Society for Minimally Invasive Spine Surgery 2017, Society for Minimally Invasive Spine Surgery 2016, Cervical Spine Research Society 2016, North American Spine Society 2016, International Society for the Advancement of Spine Surgery 2016, Cervical Spine Research Society 2015, and North American Spine Society 2015.

\section{Correspondence}

Kern Singh: Rush University Medical Center, Chicago, IL. kern. singh@rushortho.com. 